South African Journal of Geomatics, Vol. 7. No. 3, November 2018

\title{
Improving Traverse Redundancy and Precision by Running on Double lines
}

\author{
Akajiaku Chukwunyere Chukwuocha Ph.D. ${ }^{1}$ and Franklin Enyinnaya Onyeagoro ${ }^{2}$ \\ ${ }^{1}$ Department of Surveying and Geoinformatics, \\ Federal University of Technology, Owerri, ac.chukwuocha@gmail.com \\ ${ }^{2}$ Geoenvironsafe Mapping Solutions, Owerri, Nigeria, onyeagorofranklin@gmail.com
}

\section{DOI: http://dx.doi.org/10.4314/sajg.v7i3.13}

\begin{abstract}
Good redundancy is required in measured quantities to isolate gross errors and improve the qualities of derived parameters. Improving the weak redundancies of traditional traverses by traversing on double lines is now possible with total stations which provide for less cumbersome measurements than previously possible and more so now that control traverses are computed by least squares adjustment using readily available computer software. Traversing on double lines requires some care in choosing traverse stations with inter-visibility to two immediately preceding and two directly succeeding stations from the instrument station. Traverses were run on double lines resulting in redundancy increase of seven per station. Local accuracy precision parameters improved also by as much as $25 \%$ and $52 \%$ with implementation at $30 \%$ and $100 \%$ of the traverse stations respectively. A chart that may be used to determine percentage number of traverse stations where traversing on double lines would be implemented to achieve set local accuracy improvements is presented.
\end{abstract}

Key words: traverse, redundancy, precision, total station, control surveys, traversing on double lines, gross errors

\section{Introduction}

All measurements contain errors as can be seen in the continuing differences between repeated measurements even after all systematic errors have been removed. It is the persistent and random nature of these remaining errors that make redundancies necessary in higher precision measurement systems as the only way to discover small sized blunders and minimize the impact of the random errors. Measurements with higher redundancies are generally more reliable as the character of the distribution of the random errors are clearer and together with other derivatives reveal very important characteristics of the measurements which make minimization of the influence of the random errors more accurate.

The word redundancy is used in two ways. The first is when redundancy refers to the total number of observations minus the minimum required to fix the model uniquely (Hashimi, 2004). In the second case Degrees of freedom (DoF) is a statistic that defines the redundancy of a least 
squares adjustment and it equals the number of measurements minus the number of unknown parameters to be estimated (Anzilic Committee on Surveying and Mapping, 2014). In this paper it is the first sense that is implied when the word redundancy is used except expressly stated.

Modern measurement science encourages higher redundancies in measurements by observing additional quantities in the systems. Ghilani (2010) describes two terms indicative of the strength or otherwise of redundancies in a measurement system. The first is the redundancy number with values between 0 and 1 and the second is the relative redundancy of the adjustment which is the total number of redundant observations in the system divided by the number of observations. If redundancy number is large $(\approx 1)$, the blunder greatly affects the residual and should be easy to find. If redundancy number is small $(\approx 0)$, the blunder has little affect on the residual and will be hard to find. And in the third case if redundancy number is zero $(=0)$, the blunder is undetectable and the parameters will be incorrect since the error has not been detected.

Improvement of precision in measurement systems is desirable as it reduces the ambiguity in the measurements. Modern studies in deformation surveys such as Beshr, A. A. E. (2015), show that improved precision implies earlier detection of movements since small amounts of deviation are detectable. Additionally such exercises as survey and alignment of large linear colliders (Herty and Albert, 2002) require very high precision surveys giving credence to the need of modern procedures that improve precision as the method being discussed here. It is also in the pursuit of improved traverse precision and precision reporting that Deakin (2012) developed some new and relatively easier procedures for reporting on the quality of traverses. This paper being presented here pursues the same goal of traverse precision improvement.

\subsection{Background of Study}

Of the three classical methods of control surveying, triangulation, traversing and trilateration, traversing is the enduring one. With advances in surveying by Global Navigation Satellite Systems (GNSS) classical triangulation and trilateration appear to have been largely rested. Traversing persists because it has been the suitable method of control densification in the shorter ranges and still provides opportunities and precision not yet replaced by the satellite methods. There are continuing needs to improve the quality of traverses for such uses as s expressed in Amiri-Simkooei et al (2012).

All traverses that start from and close on known stations have the same redundancy of 3 (Deakin, 2012). Compare this with a triangulation scheme of a braced quadrilateral with two controls in which eight angles and a baseline are observed. The redundancy in the system will be five from nine observations and four unknowns. The more other braced quadrilaterals are added the more the redundancy will increase in triangulation. For GNSS survey of a braced quadrilateral in which a point is held fixed the number of measurements is 18 (three per baseline) and the number of unknowns is 9 (three each for the three marks that need to be fixed). This results in a redundancy of nine (Anzilic Committee on Surveying and Mapping, 2014). The more the stations in this network increases the more the degree of freedom increases too. So comparatively and not minding other 
strengths, redundancy in traversing is very low and generally fixed at three and does not increase by increase in number of stations. The desirability to increase redundancy in traverse measurements is compelling.

Previous efforts to improve redundancies in control traverses include the double run method which involves establishing two stations about 3m apart at every other traverse station thus creating a system of triangles (Wyman, 1999). This involved increasing setup stations by up to 50\% auxiliary stations and introduced further directional errors by observing lines of distances as short as $3 \mathrm{~m}$. The effort to establish these double points was made to reduce the cumbersome distance measurement by dragging invar tapes in the earlier days of classical control traversing. These limitations may explain why the practice is no longer common.

Modern provisions to improve redundancy in traverses come from some standards and guides which provide that control traverses should be run by cross-ties, for example to several right of way or land net monuments into the control network to establish a network of interconnected (redundant) control points whenever possible. This will enable the establishment of a strong geometric figure and provide redundant observations which will take advantage of using a least squares adjustment. The traverse network should include multiple triangles (Land Surveying, Mapping and GIS Section 2008, Office of Land Surveys 2016, Total Station System (TSS) Survey Specification 2005).

The foregoing provisions recommend increase in redundancies in control traversing, but only "whenever possible". There have not been any structured provisions on how traverse redundancies can be increased in a practically viable way. The aim of the new method being introduced is to increase redundancies in a sustainable way so as to ensure that control traverses take advantage of higher redundancies in networks.

\subsection{Theoretical Concept of the New Method}

A traverse angle is measured at a first station between a preceding line (line 1) and a succeeding one line (line 2). The angle and the two lines define a triangle shape with only a missing but defined line. That missing line can be measured from the end of line 2, at the second traverse station and so the triangle is completed. Traverses can thus be made a system of succeeding triangles instead of succeeding lines by sighting two consecutive preceding stations and two sequential succeeding stations. This is the method of traversing on double lines.

Figure 1 illustrates the scheme of control traversing on double lines together with the measured quantities. While there are sightings to four stations six angles are derived. Using the different combinations of the four directions from the sightings is valid for increasing redundancy since the different angles that are produced by the different combinations of the sightings will yield different sizes and signs of random errors and thus further reveal the character of the random errors in those sightings. 


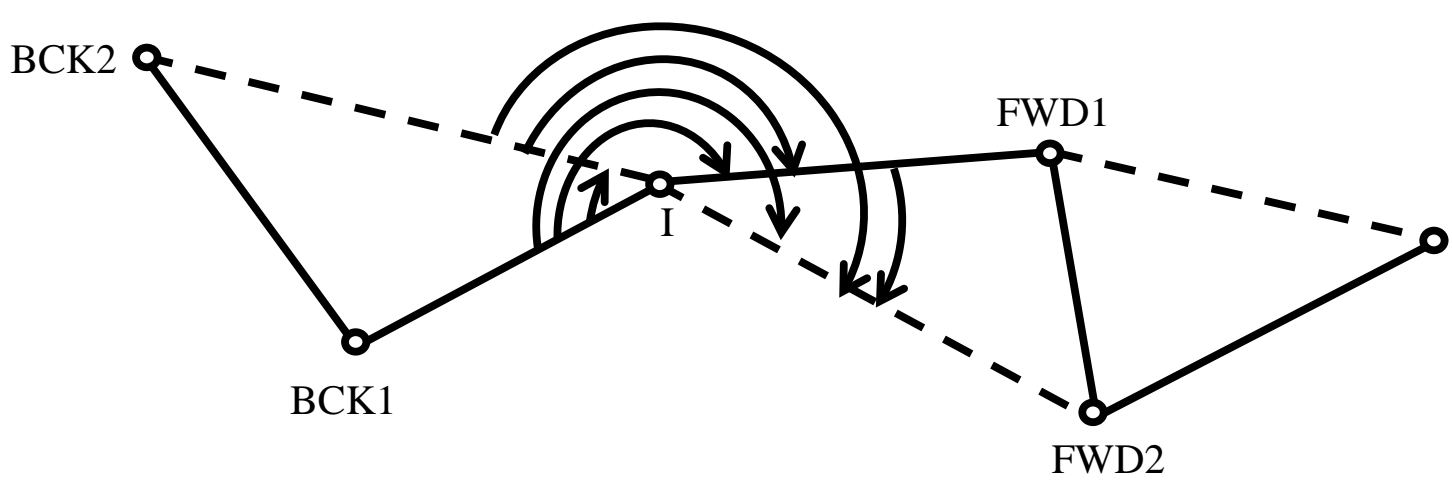

Figure 1. Scheme of Traversing on Double Lines Showing the Measured Quantities at a Station, I

In Figure 1 observation of double lines from instrument station I backwards and forward is shown. The main traverse legs I to immediate backward station BCK1 and immediate forward stations FWD1 are shown in continuous lines and the additional sightings to second backward and forward stations BCK2 and FWD2 are shown in dashed lines. Instead of the usual one angle and two distances measured at a station a complete measurement of all double line quantities will produce seven additional measurements from six angles and four distances.

The field operations of running traverse on double line and movement of instruments and targets will remain as it is in the traditional traversing. At every move of the instrument station to the next only the very last target moves to the foremost station. The forced centering method which is the recommended method of control traversing is used (Survey Department of Siri Lanka, 2014). The new method will require a little more care in choosing traverse stations so that they are visible from the previous two and succeeding two. The method can still be run even when only a single back or fore sight is feasible. Improved redundancy and precision will still be achieved if for some circumstances implementing the observation of double lines is only possible from some stations.

While the method being proposed will present some challenges to fully implement in forested areas or difficult topographies, it is fully implementable in small area surveys that require high precision such as in construction deformation monitoring. Such a project is reported in Hope \& Chuaqui (2007) on total station monitoring of movements of constructions. This involved total station measurements on the high rise with a foundation that was seven-stories which occupied an old, open parking lot next to several sensitive and/or significant buildings. Sixty-five targets placed on surrounding structures were monitored with a total station theodolite, and the report stressed the need for high precision which the method of traversing on double lines would enhance.

\section{Materials and methods}

Two traverses run to demonstrate the feasibility of the method of traversing by observing double lines are reported here. The first traverse was of traverse leg distances of between $100 \mathrm{~m}$ and $240 \mathrm{~m}$, with a total traverse length of $840 \mathrm{~m}$. The second traverse of total length of $2.9 \mathrm{Km}$ was set to meet second order criteria and the legs were of lengths $250 \mathrm{~m}$ to $550 \mathrm{~m}$. The traverse field observations were made using a 2" total station on four reflector targets. Distance measurement was set on 
refinement mode of average of 3 readings and the general atmospheric correction factors were set for the total station. Field observation of angles and distances were by the forced centering method. Angles were estimated by an average of 5 zeroes on both faces. Grid distances on the Nigerian Transverse (modified) Mercator map projection system were determined from the mean of field measured distances. All angular values in this work are in the sexagesimal (degrees, minutes, and seconds) unit while all distances and coordinates in the meter unit except otherwise explicitly indicated.

Table 1 presents the coordinates of the control stations used in the computation of the two traverses. All the controls used in the traverses were established using dual frequency GNSS receivers in the fast static mode. Trimble Business Center ${ }^{\mathrm{TM}}$ GNSS software (Trimble Engineering and Construction Group 2011) was used to process the GNSS data in the fixed solution mode and all the coordinates were determined in the projected Nigeria (modified) Transverse Mercator map system after network adjustment. The orthometric heights were determined on the OSU 91A geoid and by a determined constant for Owerri they are here produced with reference to the Lagos mean sea level datum.

Table 1. Coordinates of Traverse Control Stations

\begin{tabular}{|c|c|c|c|c|c|c|}
\hline Point ID & $\begin{array}{c}\text { Easting } \\
\text { (Meter) }\end{array}$ & $\begin{array}{c}\text { Easting Error } \\
\text { (Meter) }\end{array}$ & $\begin{array}{c}\text { Northing } \\
\text { (Meter) }\end{array}$ & $\begin{array}{c}\text { Northing Error } \\
\text { (Meter) }\end{array}$ & $\begin{array}{c}\text { Elevation } \\
\text { (Meter) }\end{array}$ & $\begin{array}{c}\text { Elevation Error } \\
\text { (Meter) }\end{array}$ \\
\hline GPS001 & 509424.481 & 0.009 & 167528.214 & 0.010 & 119.528 & 0.044 \\
\hline GPS002 & 509546.442 & 0.009 & 167214.132 & 0.011 & 113.565 & 0.043 \\
\hline GPS009 & 509704.693 & 0.002 & 166412.574 & 0.003 & 84.503 & 0.008 \\
\hline GPS010 & 509745.463 & 0.002 & 165939.759 & 0.003 & 73.778 & 0.008 \\
\hline GPSD001 & 508726.654 & 0.001 & 167021.323 & 0.001 & 78.751 & 0.002 \\
\hline GPSD002 & 509010.418 & 0.001 & 167387.897 & 0.001 & 98.656 & 0.002 \\
\hline GPSD010 & 509784.282 & 0.001 & 165747.850 & 0.001 & 71.808 & 0.005 \\
\hline GPSD012 & 509821.628 & 0.002 & 165174.971 & 0.001 & 69.094 & 0.005 \\
\hline
\end{tabular}

Field measured quantities used in the computation of the traverses are presented in Table 2. The grid distances of the traverses and the mean of all angles observed at each station were used in the computations. The first traverse was run beginning from instrument set up at station GPS 002 with a back sight to GPS 001 and run successively on stations PT3, PT4, PT5, PT6, PT7, PT8 and closed on control station GPS 009 with a forward sight to control station GPS010. The traverse was run on double lines. The second order $2.9 \mathrm{Km}$ long traverse was run with takeoff at control station GPSD002 and a back sight to GPSD001 and then run on stations RT3, RT4, RT5, RT6, RT7, RT8 and RT9 with closing setup on control station GPS010 and a forward sight to GPSD012.

It was not possible to observe full double lines at all the stations. At station RT3 double lines could only be observed to forward stations RT4 and RT5 with a single back station sight to GPSD002. At station RT4 also a single back sight could only be taken to station RT4 with forward double lines observed to stations RT5 and RT6. At station RT9, double back sight shots were taken to RT7 and RT8, but a single forward sight to control station GPSD010.

The computation of the two traverses were carried out to compare the results of the traverses using the traditional single line traverses with the results of the traverses on double lines when implemented at $100 \%, 90 \%, 70 \%, 50 \%$ and $30 \%$ of the stations. The traditional single line traverses 
were also computed for both cases by removing all extra observations and using only the traditional traverse quantities for comparison. The traverse computations were executed by least squares adjustment using Adjust software (Ghilani 2010). Table 3 presents the result of the first traverse of $840 \mathrm{~m}$ length. Table 4 presents the result of the second order traverse of $2.9 \mathrm{Km}$ length.

Each station coordinate was derived together with the accuracy statistics such as the standard deviations in the eastings and northings, the semi major and semi minor axes of the error ellipses at the $95 \%$ confidence level and also the radius of the error circle at the $95 \%$ confidence level and lastly the local accuracy of the traverse. For convenience so that the different qualities of the different traverses will be apparent, the precision of the traverses were reported using local accuracy value.

Table 2. Field Determined Quantities of the Traverses

\begin{tabular}{|c|c|c|c|c|c|c|c|c|c|}
\hline \multicolumn{5}{|c|}{ First Traverse: 840m Long Traverse } & \multicolumn{5}{|c|}{ Second Order 2.9Km Long Traverses } \\
\hline BCK & STN & FWD & Angle “، & $\begin{array}{c}\text { Grid } \\
\text { Distance } \\
\text { STN to } \\
\text { FWD (m) }\end{array}$ & BCK & STN & FWD & Angle & $\begin{array}{c}\text { Grid } \\
\text { Distance } \\
\text { STN to } \\
\text { FWD (m) }\end{array}$ \\
\hline GPS001 & GPS002 & PT3 & 168528.9 & 113.590 & GPSD001 & GPSD002 & RT3 & 20431 & 406.323 \\
\hline GPS001 & GPS002 & PT4 & 1852546.5 & 240.702 & GPSD002 & RT3 & RT4 & 26642 & 267.511 \\
\hline PT3 & GPS002 & PT4 & 0163334.1 & 240.702 & RT4 & RT3 & RT5 & 00316 & 515.871 \\
\hline GPS002 & PT3 & PT4 & 2102139.3 & 135.745 & RT3 & RT4 & RT5 & 18647 & 249.270 \\
\hline GPS002 & PT3 & PT5 & 2024609.1 & 273.016 & RT5 & RT4 & RT6 & 008175.4 & 536.646 \\
\hline GPS001 & PT3 & PT4 & 2020144.4 & 135.745 & RT3 & RT4 & RT6 & 19504 & \\
\hline GPS001 & PT3 & PT5 & 1942614.2 & 273.016 & RT4 & RT5 & RT6 & 19520 & 292.211 \\
\hline GPS002 & PT3 & GPS001 & 0081954.9 & & RT6 & RT5 & RT7 & 0032943 & 544.014 \\
\hline PT5 & PT3 & PT4 & 073530.2 & 135.745 & RT3 & RT5 & RT7 & 20221 & \\
\hline PT3 & PT4 & PT5 & 1650156.9 & 139.620 & RT3 & RT5 & RT6 & 19851 & \\
\hline PT3 & PT4 & PT6 & 1742323.5 & 239.939 & RT4 & RT5 & RT7 & 19850 & \\
\hline GPS002 & PT4 & PT5 & 1784949.8 & 139.620 & RT3 & RT5 & RT4 & 00330 & 249.271 \\
\hline GPS002 & PT4 & PT6 & $18811 \quad 16.4$ & 239.939 & RT5 & RT6 & RT7 & 187320.9 & 252.983 \\
\hline GPS002 & PT4 & PT3 & 0134752.9 & 135.745 & RT5 & RT6 & RT8 & 18156 & \\
\hline PT5 & PT4 & PT6 & 0092126.6 & 239.939 & RT4 & RT6 & RT7 & 19435 & \\
\hline PT4 & PT5 & PT6 & 2015245.1 & 104.678 & RT4 & RT6 & RT8 & 18900 & 542.123 \\
\hline PT4 & PT5 & PT7 & 1892740.5 & 207.212 & RT4 & RT6 & RT5 & 070341.6 & 292.213 \\
\hline PT3 & PT5 & PT6 & 1942954.7 & 104.678 & RT8 & RT6 & RT7 & 00535 & \\
\hline PT3 & PT5 & PT7 & 1820450.1 & 207.212 & RT6 & RT7 & RT8 & 16933 & 291.388 \\
\hline PT4 & PT5 & PT3 & 0072250.4 & 273.016 & RT6 & RT7 & RT9 & 17356 & \\
\hline PT7 & PT5 & PT6 & 0122504.6 & 104.678 & RT5 & RT7 & RT8 & 17335 & \\
\hline PT5 & PT6 & PT7 & 1552837.7 & 107.373 & RT5 & RT7 & RT9 & 17759 & \\
\hline PT5 & PT6 & PT8 & 1690643.5 & 227.934 & RT5 & RT7 & RT6 & 00402 & 252.982 \\
\hline PT4 & PT6 & PT7 & 1680001.3 & 107.373 & RT8 & RT7 & RT9 & 00423 & 549.432 \\
\hline PT4 & PT6 & PT8 & 1813807.1 & 227.934 & & RT8 & RT7 & & 291.389 \\
\hline PT4 & PT6 & PT5 & 0123123.6 & 104.678 & RT7 & RT8 & RT9 & 1891821 & 259.856 \\
\hline PT7 & PT6 & PT8 & 133805.8 & 227.934 & RT7 & RT8 & GPSD010 & 18509 & \\
\hline PT6 & PT7 & PT8 & 2051234.4 & 126.166 & RT6 & RT8 & RT9 & 18427 & \\
\hline PT6 & PT7 & GPS009 & 1932628.2 & 232.293 & RT6 & RT8 & GPSD010 & 18017 & 549.355 \\
\hline PT5 & PT7 & PT8 & 1930619.6 & 126.166 & RT7 & RT8 & RT6 & 045101.2 & \\
\hline PT5 & PT7 & GPS009 & 1812013.4 & 232.293 & GPSD010 & RT8 & RT9 & $\begin{array}{l}040920.1 \\
\end{array}$ & \\
\hline PT6 & PT7 & PT5 & 0120614.8 & 207.212 & RT8 & RT9 & GPSD010 & 17207 & 290.791 \\
\hline GPS009 & PT7 & PT8 & 0114606.2 & 126.166 & RT7 & RT9 & GPSD010 & 17702 & 290.793 \\
\hline PT7 & PT8 & GPS009 & 1545526.8 & 111.794 & RT7 & RT9 & RT8 & 045511.7 & 259.854 \\
\hline PT7 & PT8 & GPS010 & 1664242.8 & 583.447 & RT9 & GPSD010 & GPSD012 & 18637 & \\
\hline PT6 & PT8 & GPS009 & 1662949.7 & 111.794 & RT8 & GPSD010 & GPSD012 & 18254 & \\
\hline PT6 & PT8 & GPS010 & 1781705.7 & 583.447 & RT9 & GPSD010 & RT8 & 034250.9 & \\
\hline PT6 & PT8 & PT7 & 0113422.9 & 126.166 & & & & & \\
\hline GPS009 & PT8 & GPS010 & 0114716 & 583.447 & & & & & \\
\hline PT8 & GPS009 & GPS010 & 1943259.3 & & & & & & \\
\hline PT7 & GPS009 & PT8 & 3464126.7 & 111.794 & & & & & \\
\hline PT7 & GPS009 & GPS010 & 1811426 & & & & & & \\
\hline PT8 & GPS009 & PT7 & 131833.3 & 232.293 & & & & & \\
\hline & & & & & & & & & \\
\hline
\end{tabular}


The local positional accuracy of a control point is a number that represents the uncertainty, at the 95\% confidence level in the coordinates of this control point relative to the coordinates of other directly connected or measured adjacent control points. The reported local accuracy is an approximate average of the individual local accuracy values between this control point and other observed control points used to establish the coordinates of the control point (Surveys Division 2013).

Table 3. Results of the Least Squares Adjustment of the 840m Long Traverses

\begin{tabular}{|c|c|c|c|c|c|c|c|c|c|}
\hline \multicolumn{10}{|c|}{ Results of the traditional traversing on single lines on all stations } \\
\hline Station & $\mathrm{X}$ & $\mathrm{Y}$ & Sx & Sy & $\mathrm{Su}$ & Sv & $\mathrm{t}$ & r(95 & \multirow{3}{*}{$\begin{array}{r}\text { Local } \\
\text { Accuracy: }\end{array}$} \\
\hline PT3 & 509607.227 & 167118.176 & 0.0024 & 0.0033 & 0.0037 & 0.0017 & $149.22^{\circ}$ & 0.0075 & \\
\hline PT4 & 509611.947 & 166982.515 & 0.0034 & 0.0045 & 0.0047 & 0.0032 & $162.56^{\circ}$ & 0.0100 & \\
\hline PT5 & 509652.676 & 166848.969 & 0.0040 & 0.0051 & 0.0051 & 0.0039 & $166.21^{\circ}$ & 0.0113 & \multirow[t]{4}{*}{0.0096} \\
\hline PT6 & 509643.704 & 166744.678 & 0.0039 & 0.0051 & 0.0051 & 0.0039 & $167.53^{\circ}$ & 0.0112 & \\
\hline PT7 & 509679.734 & 166643.532 & 0.0033 & 0.0047 & 0.0047 & 0.0032 & $170.69^{\circ}$ & 0.0100 & \\
\hline PT8 & 509667.420 & 166517.970 & 0.0020 & 0.0035 & 0.0037 & 0.0017 & $161.44^{\circ}$ & 0.0075 & \\
\hline \multicolumn{9}{|c|}{ Results of traversing on double lines at $100 \%$ of all traverse stations } & \multirow{8}{*}{$\begin{array}{r}\text { Local } \\
\text { Accuracy: } \\
0.0046\end{array}$} \\
\hline Station & $X$ & $\mathrm{Y}$ & Sx & Sy & $\mathrm{Su}$ & $\mathrm{Sv}$ & $\mathrm{t}$ & $\mathrm{r}(95 \%)$ & \\
\hline PT3 & 509607.228 & 167118.175 & 0.0013 & 0.0019 & 0.0021 & 0.0010 & $152.02^{\circ}$ & 0.0042 & \\
\hline PT4 & 509611.950 & 166982.511 & 0.0015 & 0.0022 & 0.0023 & 0.0014 & $162.17^{\circ}$ & 0.0047 & \\
\hline PT5 & 509652.682 & 166848.968 & 0.0017 & 0.0024 & 0.0024 & 0.0016 & $165.97^{\circ}$ & 0.0051 & \\
\hline PT6 & 509643.710 & 166744.673 & 0.0016 & 0.0024 & 0.0024 & 0.0016 & $166.47^{\circ}$ & 0.0051 & \\
\hline PT7 & 509679.739 & 166643.530 & 0.0014 & 0.0022 & 0.0022 & 0.0014 & $168.95^{\circ}$ & 0.0046 & \\
\hline PT8 & 509667.423 & 166517.968 & 0.0010 & 0.0018 & 0.0019 & 0.0009 & $162.31^{\circ}$ & 0.0038 & \\
\hline \multicolumn{9}{|c|}{ Results of traversing on double lines at $90 \%$ of all traverse stations } & \multirow{8}{*}{$\begin{array}{r}\text { Local } \\
\text { accuracy: } \\
0.0050\end{array}$} \\
\hline Station & $\mathrm{X}$ & $\mathrm{Y}$ & Sx & Sy & $\mathrm{Su}$ & Sv & $\mathrm{t}$ & $\mathrm{r}(95$ & \\
\hline PT3 & 509607.229 & 167118.175 & 0.0014 & 0.0021 & 0.0023 & 0.0010 & $152.41^{\circ}$ & 0.0046 & \\
\hline PT4 & 509611.951 & 166982.509 & 0.0016 & 0.0027 & 0.0027 & 0.0015 & $162.22^{\circ}$ & 0.0056 & \\
\hline PT5 & 509652.683 & 166848.967 & 0.0018 & 0.0026 & 0.0026 & 0.0017 & $164.83^{\circ}$ & 0.0055 & \\
\hline PT6 & 509643.711 & 166744.672 & 0.0017 & 0.0025 & 0.0026 & 0.0016 & $164.97^{\circ}$ & 0.0054 & \\
\hline PT7 & 509679.739 & 166643.530 & 0.0014 & 0.0022 & 0.0023 & 0.0014 & $168.33^{\circ}$ & 0.0047 & \\
\hline PT8 & 509667.423 & 166517.968 & 0.0011 & 0.0018 & 0.0019 & 0.0009 & $161.89^{\circ}$ & 0.0038 & \\
\hline \multicolumn{9}{|c|}{ Results of traversing on double lines at $70 \%$ of all traverse stations } & \multirow{8}{*}{$\begin{array}{r}\text { Local } \\
\text { Accuracy: } \\
0.0052\end{array}$} \\
\hline Station & $\mathrm{X}$ & $\mathrm{Y}$ & Sx & Sy & $\mathrm{Su}$ & Sv & $\mathrm{t}$ & r(95\%) & \\
\hline PT3 & 509607.229 & 167118.174 & 0.0014 & 0.0021 & 0.0023 & 0.0010 & $152.03^{\circ}$ & 0.0047 & \\
\hline PT4 & 509611.952 & 166982.509 & 0.0017 & 0.0027 & 0.0028 & 0.0015 & $161.51^{\circ}$ & 0.0057 & \\
\hline PT5 & 509652.684 & 166848.967 & 0.0018 & 0.0026 & 0.0027 & 0.0017 & $163.20^{\circ}$ & 0.0057 & \\
\hline PT6 & 509643.712 & 166744.672 & 0.0018 & 0.0026 & 0.0027 & 0.0017 & $163.42^{\circ}$ & 0.0056 & \\
\hline PT7 & 509679.740 & 166643.529 & 0.0015 & 0.0023 & 0.0024 & 0.0015 & $165.63^{\circ}$ & 0.0050 & \\
\hline PT8 & 509667.424 & 166517.968 & 0.0012 & 0.0021 & 0.0022 & 0.0010 & $162.80^{\circ}$ & & \\
\hline \multicolumn{9}{|c|}{ Results of traversing on double lines at $50 \%$ of all traverse stations } & \multirow{8}{*}{$\begin{array}{r}\text { Local } \\
\text { Accuracy: } \\
0.0064\end{array}$} \\
\hline Station & $X$ & $\mathrm{Y}$ & Sx & Sy & $\mathrm{Su}$ & $\mathrm{Sv}$ & $\mathrm{t}$ & $\mathrm{r}(95 \%)$ & \\
\hline PT3 & 509607.228 & 167118.176 & 0.0015 & 0.0022 & 0.0025 & 0.0010 & $151.62^{\circ}$ & 0.0050 & \\
\hline PT4 & 5096 & 166982.511 & 0.0018 & 0.0030 & 0.0031 & 0.0016 & $161.41^{\circ}$ & 0.0064 & \\
\hline PT5 & 509652.681 & 166848.971 & 0.0021 & 0.0031 & 0.0032 & 0.0020 & $162.39^{\circ}$ & 0.0067 & \\
\hline PT6 & 509643.708 & 166744.676 & 0.0022 & 0.0032 & 0.0032 & 0.0021 & $164.25^{\circ}$ & 0.0068 & \\
\hline PT7 & 509679.735 & 166643.534 & 0.0023 & 0.0034 & 0.0035 & 0.0022 & $161.85^{\circ}$ & 0.0073 & \\
\hline PT8 & 509667.419 & 166517.975 & 0.0018 & 0.0030 & 0.0032 & 0.0015 & $161.13^{\circ}$ & 0.0064 & \\
\hline \multicolumn{9}{|c|}{ Results of traversing on double lines at $30 \%$ of all traverse stations } & \multirow{8}{*}{$\begin{array}{r}\text { Local } \\
\text { Accuracy: } \\
0.0075\end{array}$} \\
\hline Station & $\mathrm{X}$ & $\mathrm{Y}$ & $\mathrm{Sx}$ & Sy & $\mathrm{Su}$ & Sv & l & r(95\%) & \\
\hline PT3 & 509607.227 & 167118.176 & 0.0016 & 0.0023 & 0.0026 & 0.0012 & $150.68^{\circ}$ & 0.0052 & \\
\hline PT4 & 509611.950 & 166982.513 & 0.0023 & 0.0032 & 0.0033 & 0.0021 & $160.46^{\circ}$ & 0.0070 & \\
\hline PT5 & 509652.680 & 166848.971 & 0.0032 & 0.0035 & 0.0036 & 0.0030 & $150.88^{\circ}$ & 0.0082 & \\
\hline PT6 & 509643.706 & 166744.679 & 0.0034 & 0.0037 & 0.0038 & 0.0033 & $161.77^{\circ}$ & 0.0087 & \\
\hline PT7 & 509679.734 & 166643.534 & 0.0029 & 0.0040 & 0.0041 & 0.0029 & $167.91^{\circ}$ & 0.0087 & \\
\hline PT8 & 509667.419 & 166517.974 & 0.0019 & 0.0034 & 0.0035 & 0.0016 & $161.72^{\circ}$ & 0.0071 & \\
\hline
\end{tabular}

Note 1: All values in this table except for $t$ are in meters

Note 2: $\mathrm{X}$ and $\mathrm{Y}=$ Easting and Northing coordinates respectively; Sx and Sy = standard error in the $\mathrm{X}$ and $\mathrm{Y}$ coordinates respectively; $\mathrm{Su}$ and $\mathrm{Sv}=$ Semi major and Semi minor radii of the error ellipse respectively; $\mathrm{t}=$ azimuth of error ellipse; r(95\%) is the radius of the error circle at $95 \%$ confidence level. 
Table 4. Results of the Least Squares Adjustment of the Second Order 2.9Km Traverses

\begin{tabular}{|c|c|c|c|c|c|c|c|c|c|}
\hline \multicolumn{10}{|c|}{ Results of traditional traversing on single lines at all traverse stations } \\
\hline Station & $\mathrm{X}$ & $\mathrm{Y}$ & Sx & Sy & Su & Sv & $\mathrm{t}$ & $\mathrm{r}(95 \%)$ & \\
\hline RT3 & 509370.074 & 167576.964 & 0.0037 & 0.0044 & 0.0049 & 0.0030 & $146.94^{\circ}$ & 0.0103 & \multirow{7}{*}{$\begin{array}{c}\text { Local } \\
\text { Accuracy: } \\
0.0137\end{array}$} \\
\hline RT4 & 509507.932 & 167347.710 & 0.0045 & 0.0054 & 0.0054 & 0.0045 & $6.05^{\circ}$ & 0.0122 & \\
\hline RT5 & 509610.222 & 167120.395 & 0.0065 & 0.0057 & 0.0069 & 0.0051 & $58.49^{\circ}$ & 0.0150 & \\
\hline RT6 & 509655.331 & 166831.687 & 0.0081 & 0.0054 & 0.0084 & 0.0050 & $71.30^{\circ}$ & 0.0175 & \\
\hline RT7 & 509661.275 & 166578.773 & 0.0083 & 0.0049 & 0.0085 & 0.0046 & $75.75^{\circ}$ & 0.0174 & \\
\hline RT8 & 509720.787 & 166293.527 & 0.0068 & 0.0041 & 0.0069 & 0.0039 & $78.95^{\circ}$ & 0.0142 & \\
\hline RT9 & 509732.026 & 166033.911 & 0.0042 & 0.0030 & 0.0043 & 0.0029 & $76.39^{\circ}$ & 0.0091 & \\
\hline \multicolumn{10}{|c|}{ Results of traversing on double lines at $100 \%$ of all traverse stations } \\
\hline Station & $X$ & $\mathrm{Y}$ & Sx & Sy & $\mathrm{Su}$ & Sv & $\mathrm{t}$ & $\mathrm{r}(95 \%)$ & \multirow{8}{*}{$\begin{array}{l}\text { Local } \\
\text { Accuracy: } \\
0.0077\end{array}$} \\
\hline RT3 & 509370.077 & 167576.955 & 0.0032 & 0.0028 & 0.0033 & 0.0027 & $113.12^{\circ}$ & 0.0075 & \\
\hline RT4 & 509507.926 & 167347.696 & 0.0036 & 0.0027 & 0.0036 & 0.0027 & $91.75^{\circ}$ & 0.0079 & \\
\hline RT5 & 509610.213 & 167120.384 & 0.0039 & 0.0026 & 0.0040 & 0.0026 & $82.64^{\circ}$ & 0.0084 & \\
\hline RT6 & 509655.323 & 166831.680 & 0.0042 & 0.0023 & 0.0043 & 0.0023 & $81.69^{\circ}$ & 0.0087 & \\
\hline RT7 & 509661.271 & 166578.768 & 0.0041 & 0.0023 & 0.0041 & 0.0022 & $81.03^{\circ}$ & 0.0085 & \\
\hline RT8 & 509720.789 & 166293.523 & 0.0034 & 0.0018 & 0.0035 & 0.0018 & $82.21^{\circ}$ & 0.0070 & \\
\hline RT9 & 509732.029 & 166033.911 & 0.0026 & 0.0020 & 0.0026 & 0.0020 & $79.96^{\circ}$ & 0.0057 & \\
\hline \multicolumn{10}{|c|}{ Results of traversing on double lines at $90 \%$ of all traverse stations } \\
\hline Station & $\mathrm{X}$ & $\mathrm{Y}$ & Sx & Sy & $\mathrm{Su}$ & Sv & $\mathrm{t}$ & $\mathrm{r}(95 \%)$ & \\
\hline RT3 & 509370.077 & 167576.955 & 0.0033 & 0.0030 & 0.0035 & 0.0028 & $119.51^{\circ}$ & 0.0077 & \multirow{7}{*}{$\begin{array}{l}\text { Local } \\
\text { Accuracy: } \\
0.0084\end{array}$} \\
\hline RT4 & 509507.927 & 167347.697 & 0.0037 & 0.0030 & 0.0037 & 0.0030 & $95.41^{\circ}$ & 0.0082 & \\
\hline RT5 & 509610.214 & 167120.384 & 0.0042 & 0.0029 & 0.0042 & 0.0028 & $81.85^{\circ}$ & 0.0089 & \\
\hline RT6 & 509655.325 & 166831.681 & 0.0046 & 0.0027 & 0.0047 & 0.0026 & $80.86^{\circ}$ & 0.0096 & \\
\hline RT7 & 509661.273 & 166578.769 & 0.0046 & 0.0027 & 0.0046 & 0.0026 & $80.27^{\circ}$ & 0.0096 & \\
\hline RT8 & 509720.790 & 166293.524 & 0.0040 & 0.0022 & 0.0040 & 0.0022 & $81.14^{\circ}$ & 0.0082 & \\
\hline RT9 & 509732.030 & 166033.911 & 0.0031 & 0.0023 & 0.0031 & 0.0022 & $78.27^{\circ}$ & & \\
\hline \multicolumn{10}{|c|}{ Results of traversing on double lines at $70 \%$ of all traverse stations } \\
\hline Station & $X$ & $\mathrm{Y}$ & Sx & Sy & $\mathrm{Su}$ & Sv & $\mathrm{t}$ & $\mathrm{r}(95 \%)$ & \multirow{8}{*}{$\begin{array}{l}\text { Local } \\
\text { Accuracy: } \\
0.0098\end{array}$} \\
\hline RT3 & 509370.078 & 167576.954 & 0.0034 & 0.0035 & 0.0039 & 0.0029 & $136.62^{\circ}$ & & \\
\hline RT4 & 509507.927 & 167347.695 & 0.0038 & 0.0037 & 0.0039 & 0.0036 & $132.20^{\circ}$ & 0.0092 & \\
\hline RT5 & 509610.214 & 167120.381 & 0.0044 & 0.0038 & 0.0045 & 0.0037 & $74.61^{\circ}$ & 0.00101 & \\
\hline RT6 & 509655.325 & 166831.681 & 0.0054 & 0.0038 & 0.0055 & 0.0037 & $75.17^{\circ}$ & 0.0118 & \\
\hline RT7 & 509661.273 & 166578.768 & 0.0052 & 0.0035 & 0.0053 & 0.0033 & $75.84^{\circ}$ & 0.0111 & \\
\hline RT8 & 509720.787 & 166293.522 & 0.0048 & 0.0034 & 0.0048 & 0.0033 & $78.55^{\circ}$ & 0.0103 & \\
\hline RT9 & 509732.026 & 166033.910 & 0.0032 & 0.0028 & 0.0033 & 0.0028 & $69.58^{\circ}$ & 0.0074 & \\
\hline \multicolumn{10}{|c|}{ Results of traversing on double lines at $50 \%$ of all traverse stations } \\
\hline Station & $\mathrm{X}$ & $\mathrm{Y}$ & Sx & Sy & $\mathrm{Su}$ & Sv & $\mathrm{t}$ & $\mathrm{r}(95 \%)$ & \multirow{8}{*}{$\begin{array}{l}\text { Local } \\
\text { Accuracy: } \\
0.0099\end{array}$} \\
\hline RT3 & 509370.077 & 167576.956 & 0.0034 & 0.0035 & 0.0040 & 0.0029 & $138.11^{\circ}$ & & \\
\hline RT4 & 509507.925 & 167347.699 & 0.0039 & 0.0040 & 0.0041 & 0.0038 & $142.75^{\circ}$ & 097 & \\
\hline RT5 & 509610.214 & 167120.383 & 0.0045 & 0.0038 & 0.0046 & 0.0038 & $72.30^{\circ}$ & 0.0103 & \\
\hline RT6 & 509655.327 & 166831.678 & 0.0055 & 0.0039 & 0.0056 & 0.0038 & $75.45^{\circ}$ & 0.0118 & \\
\hline RT7 & 509661.274 & 166578.767 & 0.0052 & 0.0035 & 0.0053 & 0.0034 & $75.98^{\circ}$ & 11 & \\
\hline RT8 & 509720.788 & 166293.521 & 0.0048 & 0.0034 & 0.0048 & 0.0033 & $78.77^{\circ}$ & 0.0103 & \\
\hline RT9 & 509732.027 & 166033.909 & 0.0032 & 0.0028 & 0.0033 & 0.0028 & $69.86^{\circ}$ & 0.0074 & \\
\hline \multicolumn{10}{|c|}{ Results of traversing on double lines at $30 \%$ of all traverse stations } \\
\hline Station & $\mathrm{X}$ & $\mathrm{Y}$ & Sx & Sy & $\mathrm{Su}$ & Sv & $\mathrm{t}$ & $\mathrm{r}(95 \%)$ & \multirow{8}{*}{$\begin{array}{l}\text { Local } \\
\text { Accuracy: } \\
0.0103\end{array}$} \\
\hline RT3 & 509370.077 & 167576.956 & 0.0034 & 0.0036 & 0.0040 & 0.0029 & $138.46^{\circ}$ & 0.0086 & \\
\hline RT4 & 509507.925 & 167347.699 & 0.0039 & 0.0040 & 0.0041 & 0.0038 & $145.45^{\circ}$ & 97 & \\
\hline RT5 & 509610.214 & 167120.383 & 0.0045 & 0.0039 & 0.0046 & 0.0038 & $71.14^{\circ}$ & 0.0103 & \\
\hline RT6 & 509655.327 & 166831.678 & 0.0055 & 0.0040 & 0.0056 & 0.0038 & $74.77^{\circ}$ & 0.0119 & \\
\hline RT7 & 509661.274 & 166578.767 & 0.0053 & 0.0036 & 0.0054 & 0.0034 & $75.51^{\circ}$ & 0.0113 & \\
\hline RT8 & 509720.789 & 166293.522 & 0.0053 & 0.0037 & 0.0054 & 0.0036 & $77.79^{\circ}$ & 0.0114 & \\
\hline RT9 & 509732.027 & 166033.910 & 0.0039 & 0.0029 & 0.0040 & 0.0028 & $75.71^{\circ}$ & 0.0085 & \\
\hline \multicolumn{10}{|c|}{$\begin{array}{l}\text { Note 1: All values in this table except for } \mathrm{t} \text { are in meters } \\
\text { Note 2: } \mathrm{X} \text { and } \mathrm{Y}=\text { Easting and Northing coordinates respectively; } \mathrm{Sx} \text { and } \mathrm{Sy}=\text { standard error in the } \mathrm{X} \text { and } \mathrm{Y} \\
\text { ordinates respectively; Su and Sv = Semi major and Semi minor radii of the error ellipse respectively; } \mathrm{t}=\text { azimuth of } \\
\text { or ellipse; } \mathrm{r}(95 \%) \text { is the radius of the error circle at } 95 \% \text { confidence level. }\end{array}$} \\
\hline
\end{tabular}




\section{Results and discussion}

The computation of the traverse was carried out by least squares adjustment method. Adjust, a least squares adjustment software obtained from Ghilani (2010) was used. Due to high redundancy

Table 5. Comparison of Local Accuracies of Traversing on Double Lines at Different Percentage of All Stations of the Traverses

\begin{tabular}{|c|c|c|c|c|c|c|}
\hline Traverse & $\begin{array}{c}0 \% \\
\text { Traditional } \\
\text { Single Line } \\
\text { Traverse } \\
\end{array}$ & $30 \%$ & $50 \%$ & $70 \%$ & $90 \%$ & $100 \%$ \\
\hline $\begin{array}{c}\text { First Traverse: } \\
\text { 840m Long Traverse } \\
\text { (Series } 1 \text { in Figure 2) }\end{array}$ & $0.0096 \mathrm{~m}$ & $0.0075 \mathrm{~m}$ & $0.0064 \mathrm{~m}$ & $0.0052 \mathrm{~m}$ & $0.0052 \mathrm{~m}$ & $0.0050 \mathrm{~m}$ \\
\hline $\begin{array}{c}\text { Second Traverse: } \\
2^{\text {nd }} \text { Order } 2.9 K m \text { Long } \\
\text { Traverse } \\
\text { (Series } 2 \text { in Figure 2) }\end{array}$ & $0.0137 \mathrm{~m}$ & $0.0093 \mathrm{~m}$ & $0.0085 \mathrm{~m}$ & $0.0082 \mathrm{~m}$ & $0.0079 \mathrm{~m}$ & $0.0078 \mathrm{~m}$ \\
\hline
\end{tabular}

it was futile to use a non-rigorous adjustment method. Table 5 presents the local accuracies achieved in the two traverses when traversing on double lines was implemented at specified percentages of the total number of traverse stations while Figure 2 presents the cases graphically.

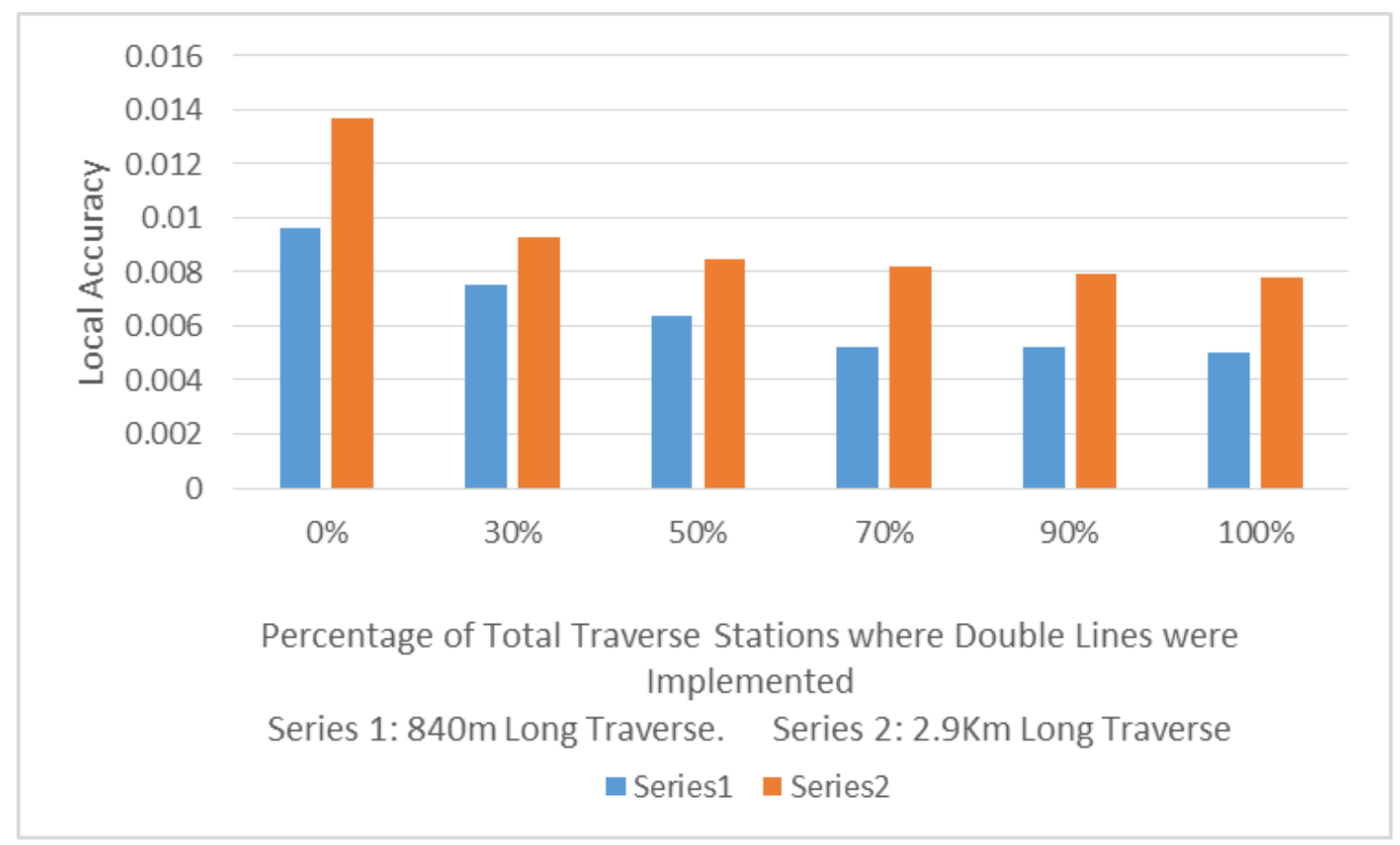

Figure 2. Improvement of Traverse Precision by Traversing on Double Lines 
The result shows significant improvement of the local accuracies at all levels from when observing on double lines was implemented at 30\% of the total number of traverse stations through to when it was implemented at $100 \%$ of the stations.

In the first traverse case there was a 22\% and 52\% improvement of local accuracies respectively at the $30 \%$ and $100 \%$ implementation level. In the $2.9 \mathrm{Km}$ long second order traverse there was a $25 \%$ improvement of local accuracy at the implementation of traversing on double lines at $30 \%$ of the stations from the zero percent implementation of the traversing on double lines, which is the traditional traversing on single lines case. At the implementation of traversing on double lines at $100 \%$ of the stations there was a $44 \%$ improvement of local accuracy from the $0 \%$ implementation of traversing on double lines, the traditional traversing on single lines case.

\section{Conclusion and recommendations}

The two closed link traverses reported here were run to demonstrate the feasibility of traversing on double lines and the significant improvements the method brings to traversing in terms of improved redundancies for tracking gross errors and to improve precision of the determined parameters. The forced centering method was used. At each set up the back sights were taken to the directly preceding two stations and forward to the two immediately succeeding stations. The simplicity of the field operations lies in the fact that just as in the traditional traversing only the last target set up would be moved to the fore as instrument station moved to a new position.

The running of traverses on double lines is promising today because the cumbersome dragging of 30m-long heavy invar tapes over double long distances has been eliminated by the use of the total station. Additionally the computation of the high redundancy traverse has been made possible by the least squares adjustment of the traverses in use today more commonly due to the availability of high speed miniaturized personal laptop computers.

The method of control traversing on double lines which by its structure may also be termed triangulated traversing has been shown to improve the redundancy in the traverse by as much as seven times the number of traverse stations when complete double lines are observed at all stations. The quality of the traverse results improved significantly by up to $52 \%$ or more in terms of the reduction in the magnitude of the variances of the coordinates and the local accuracies of the traverses.

If due to visibility problems it is not possible to observe all the double lines at any station it is still helpful to observe the intervisible additional lines. Significant improvements were recorded even when the number of stations on which double line observations were only $30 \%$. However there should be a fair spread of the points at which the double lines are observed in all the parts of the traverse otherwise undue accumulation of errors at one part of the traverse could distort the efforts.

The method of control traversing by observation of double lines is strongly recommended to be adopted for all control traverses so as to achieve higher precisions by traversing. It is further 
recommended that since a triangular figure cannot provide for the observation of double lines that all control traverses be designed to run on figures of not less than four sides.

Traversing on double lines recommends itself to studies where it is desirable to keep the uncertainties very low such as in deformation studies and projects monitoring. It must be said that for open areas and projects requiring quite higher precisions traversing on triple and quadruple and even quintuple lines are expected to further improve the already very significant marks demonstrated in this research.

\section{References}

Anzilic Committee on Surveying and Mapping (2014) “Guideline for the Adjustment and Evaluation of Survey Control" Intergovernmental Committee on Surveying and Mapping \& Permanent Committee on Geodesy Commonwealth of Australia. http://www.icsm.gov.au/publications/sp1/Guideline-forAdjustment-and-Evaluation-of-Survey-Control_v2.1.pdf

Beshr, A.A.A. (2015) Structural Deformation Monitoring and Analysis of Highway Bridge Using Accurate Geodetic Techniques. Engineering, 7, 488-498. http://dx.doi.org/10.4236/eng.2015.78045

Deakin R. (2012) Traverse Analysis. Paper presented at the Geospatial Science Research_2 Conference, Melbourne 10-12 December 2012 http://www.surveying.org.au/docs/techinfo/Rod-Deakin-Traverse-Analysis.pdf

Ghilani C. D. 2010. Adjustment Computations - Spatial data Analysis $5^{\text {th }}$ Ed. New Jersey John Wiley and Sons p.441

Hashimi S. R. (2004) Traverse Adjustment Using Microsoft Excel Solver. Paper presented at the American Congress on Surveying and Mapping and the Tennessee Association of Professional Surveyors (ACSM/TAPS) Conference April 19 - 212004 Nashville Tennessee https://www.scribd.com/document/37152956/Traverse-Adjustment-using-Excel

Herty, A. Albert, J. (2002) High Precision Survey and Alignment of Large Linear Colliders - Horizontal Alignment. Proceedings of the 7th International Workshop on Accelerator Alignment, SPring-8, 2002. www.slac.stanford.edu/econf/C0211115/papers/040.PDF

Hope, C. J. \& Chuaqui, M. (2007) Precision Surveying Monitoring of Shoring and Structures. Proceedings of the 7th International Symposium on Field Measurements in Geomechanics: September 24-27, 2007, Boston Massachusetts paper No. 105. http://monir.ca/assets/pdfs/precision_surveying_monitoring_of_shoring_and_structures.pdf

Land Surveying, Mapping and GIS Section (2008). Survey Technical Guidelines. South Florida Water Management District.

https://www.swfwmd.state.fl.us/files/database/site file sets/2682/FY14_Standard Operating_Procedure - Field.pdf p. 84

Office of Land Surveys (2016) Caltrans Surveys Manual: Control Surveys' California Department of Transportation Sacramento CA 95814 p. 9_17

http://www.dot.ca.gov/hq/row/landsurveys/SurveysManual/09_Surveys.pdf

Survey Department of Siri Lanka (2014) Departmental Survey Regulations: Horizontal and Vertical Control Network. Government of Siri Lanka www.survey.gov.lk/surveyweb/Home\%20English/.../DSR_english/Chapter\%20II.pdf

Surveys Division (2013). Requirements and Procedures For Control, Design, and Land Surveys. Arkansas Highway and Transportation DepartmentGhilani Charles. D and Wolf Paul. R. 2012. Elementary Surveying: An Introduction to Geomatics. 13 ${ }^{\text {th }}$ ed. Prentice Hall New York pp. $231-243$

https://www.arkansashighways.com/surveys division/manuals/Surveys.pdf 
South African Journal of Geomatics, Vol. 7. No. 3, November 2018

Total Station System (TSS) Survey Specification (2005) “Highway Surveying Manual” Washington State Department of Transportation.

https://www.wsdot.wa.gov/publications/manuals/fulltext/M22-97/Chapter9.pdf

Trimble Engineering and Construction Group, 2011. Trimble Business center 2.50 Software. Dayton, Ohio, U.S.A.

Wyman P. C. (1999) "Hanging Lines - Still a Problem for Surveyors" Association of Ontario Land Surveyors: Ontario Professional Surveyor Vol. 42 (1) pp17 - 18

http://www.krcmar.ca/sites/default/files/1999_Winter_Hanging\%20Lines_1.pdf 